\title{
Proportional Resonant controller based Inter Leaved Boost Converter fed Unified Power Quality Conditioner System
}

\author{
G.V. Prasanna Anjaneyulu*, P. Sangameswara Raju ** \\ * Research Scholar, EEE Department, S.V.U.C.E., S.V. University, Tirupathi, Andhra Pradesh, India \\ ** Professor, EEE Department, S.V.U.C.E., S.V. University, Tirupathi, Andhra Pradesh, India
}

Abstract- UPQC is an useful FACTS controller between sending end and receiving end for improvement of voltage quality. This work deals with identification of suitable controller for closed loop operation of ILBC based UPQC. The Analysis and comparison of responses with PI, FOPID \& PR are presented in this article. The results of PI based ILBC-UPQC systems are compared with those of FOPID\& PR controlled ILBC-UPQC system. The objective of this work is to improve the time domain response of ILBC-UPQC using suitable controller. The ILBC is proposed for UPQC since it gives better performance than HSUC and TIBC. The comparison is done in terms of rise time, peak time, settling time \& steady state error. The MATLAB results indicate superior performance with PR based ILBCUPQC system.

Keywords:Rise time, Peak time, settling time, Steady State Error

\section{A.General}

\section{INTRODUCTION}

In present day control structures, allotment utilities arrange the related weights to satisfy the strict power quality rules. This is to improve the resolute nature of the scattering structure to address the issues of essential weights and tricky robotization systems.

The genuine necessities to keep up extraordinary quality power are: 1) essential responsive power requirements of the related burdens; 2) voltage records and swells at the reason for general coupling (PCC) due to affiliation and division of tremendous mechanical weights and open power compensating capacitors; and 3) voltage or conceivably current symphonious bowing on account of the closeness of nonlinear weights. Dynamic power channels (APFs) are the most reassuring and extensively used answers for upgrading the Power Quality (PQ) at the flow level [1]-[2]. These APFs can be appointed shunt APF, course of action APF, and blend APF. The blend of both course of action and shunt APFs, to decrease most of the voltage and current related PQ issues, is a bound together Unified Power Quality Conditioner (UPQC). Preferred execution and the utmost over abatement all major PQ issues make UPQC the most appealing system for PQ change despite its high cost, complex structure, and control [1]-[3]. The structure outline of an UPQC is showed up in Figure.1.

Current examples in the zone of UPQC are facilitated toward working the UPQC with least volt ampere (VA) stacking to lessen the general structure hardships [3]-[12]. In any case, most of the uncovered work rely on upon constraining the VA stacking in the midst of voltage rundown conditions [3],[4], [7]-[12]. The evaluating some portion of the UPQC system (tallying the shunt inverter, game plan inverter, and course of action transformer) considering particular shunt and game plan inverter VA stacking under different working conditions are inspected.

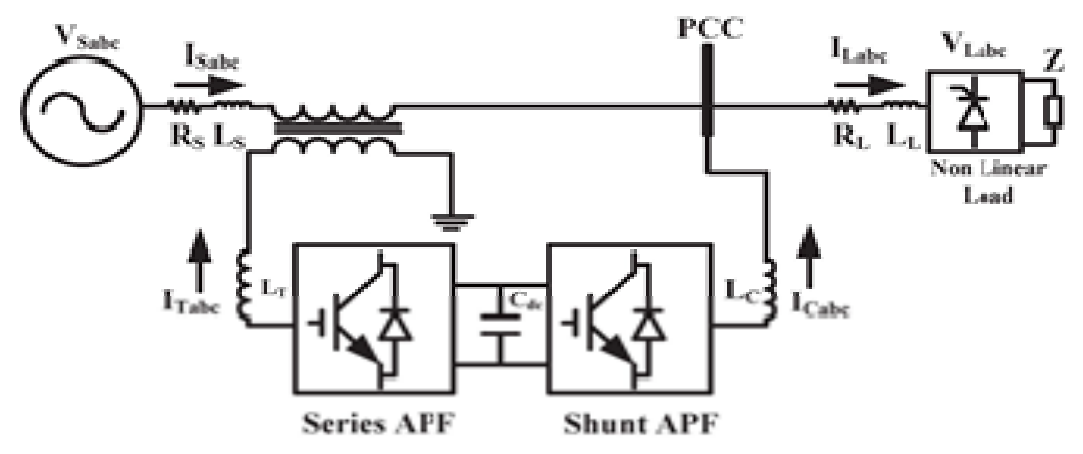

Fig.1: Schematic diagram of the Unified Power Quality Conditioner (UPQC) 
In perspective of the control technique being used for voltage rundown or swell compensations, the UPQC structures can be appointed UPQC-P, UPQC-Q, and UPQC-S [2]. The UPQC-P is thought to be a consistent UPQC, where voltage fall and swell pay are performed by implanting/holding the dynamic influence (in eliminate or of stage voltage) through the course of action some portion of the UPQC while the shunt inverter supports the load responsive influence, dynamic influence required by the plan inverter, and the adversities in the structure. For a comparative estimation of voltage hang and swell compensation, the VA loadings of course of action and shunt inverters will be most outrageous in the midst of the UPQC-P, compensating for the best voltage list. Thus, UPQC-P should be sketched out in light of the best, voltage hang compensation. While in case of UPQC-Q the voltage imbued through a game plan transformer is in quadrature with the source current. As needs be, plan inverter does not require any unique influence for reimbursing the voltage hang except for the trading and filtering setbacks. The UPQC-Q approach is obliged to voltage list compensation since it can't compensate for the voltage swell [2], [4]. For a comparable measure of rundown pay, UPQC-Q requires greater course of action imbuement voltage degree appeared differently in relation to UPQC-P [2]-[4], [7], [8]. This assembles the VA rating of the plan transformer basically.

Generally, the voltage sags and swells are brief term PQ issues. In this way, in UPQC-P and UPQC_Q, course of action inverter VA stacking might be utilized for brief terms. On the other hand, the shunt inverter VA rating is totally utilized watchful out the operation, as a result of steady load open power support and current consonant pay. To enhance the utilization of course of action some bit of UPQC in the midst of persisting state, some bit of load open power is reinforced by the game plan inverter in UPQC - S [5], \{6]. This piece of course of action inverter improves its utilization, and in addition reduces the shunt inverter VA stacking. As a result of the stack responsive power sharing component of the game plan part, the rating of the shunt inverter in UPQC-S may be not as much as that in the UPQC-P. In any case, this is to the burden of a fairly extended course of action transformer rating and diminishment in the rate of swell pay limit.

\section{B. Research Gap}

The Literature [1]-[12] does not deal with PR controlled ILBC-UPQC system. This work proposes ILBC to reduce current ripple. The Literature does not deal with PR to improve time response of closed loop controlled ILBC-UPQC system. The PR is proposed since it improves stability and reduces chaotics in output.

\section{SYSTEM CONFIGURATION}

The block diagram of proposed system is shown in Figure - 2. The capacitor of UPQC is charged by the Output of ILBC. The output voltage of PV is boosted using ILBC.The Battery is replaced by a PV system \& ILBC to produce the voltage required to charge the capacitor. ILBC is preferred to single boost converter due to reduced input current ripple.

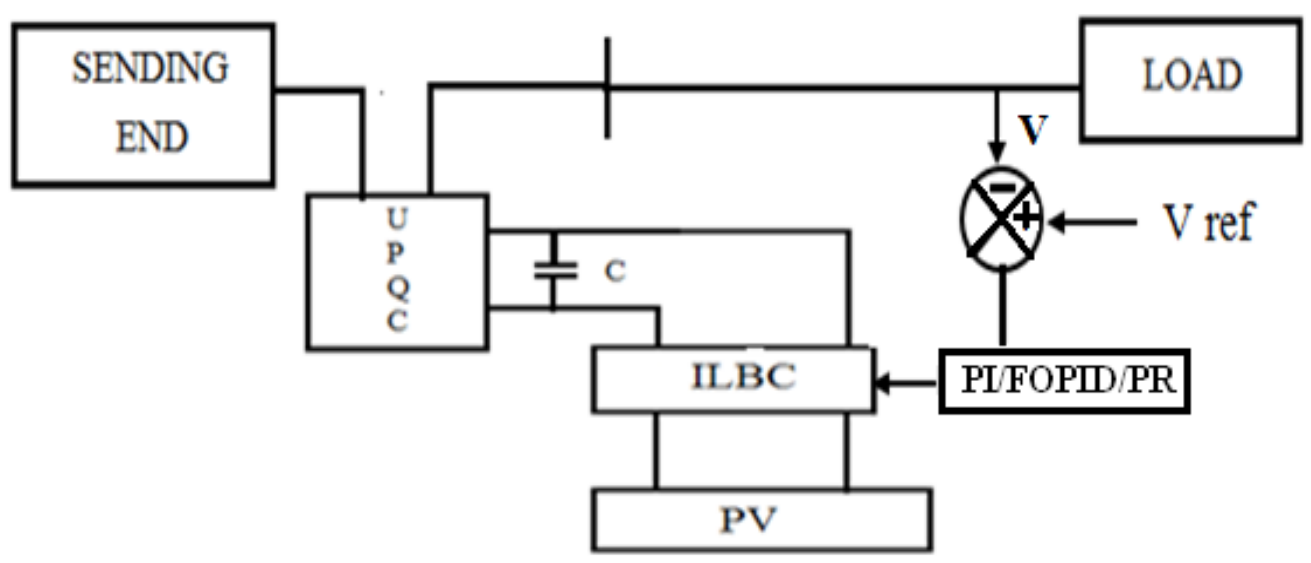

Fig.2: Block Diagram of Proposed ILBC-UPQC System

Load Voltage is sensed and it is compared with the reference voltage. The error is applied to the PI/FOPID/PR Controller. The PI/FOPID/PR updates the pulse width of ILBC to regulate the load voltage. 


\section{SYSTEM ANALYSIS}

Design is done by obtaining the values of $\mathrm{V}_{1}, \mathrm{I}_{1}$ and frequency of MOSFET. Based on required capacitor voltage, the duty ratio is calculated using the following equation

$$
\mathrm{V}_{0}=\frac{\mathrm{V}_{1}}{(1-a)}
$$

Efficiency of the converter to calculatethe output current is

$$
\eta=\frac{\mathrm{V}_{\mathrm{a}} \mathrm{I}_{\mathrm{a}}}{\mathrm{V}_{1} \mathrm{I}_{\mathrm{a}}}
$$

The values of $\mathrm{L} \& \mathrm{C}$ are calculated by assuming $\Delta \mathrm{I} \& \Delta \mathrm{V}$

$$
\begin{aligned}
& \Delta \mathrm{V}=\frac{V_{1} \mathrm{D}}{\mathrm{fL}} \\
& \Delta \mathrm{I}=\frac{\mathrm{I}_{a} \mathrm{D}}{\mathrm{fC}}
\end{aligned}
$$

Voltage to be injected is equal to IZ. The active filter is designed to supply fifth harmonic. The value of $\mathrm{C}_{5}$ is assumed and $\mathrm{L}_{5}$ is calculated with formula

$$
f_{5}=\frac{1}{2 \pi\left(\mathrm{L}_{5} \mathrm{C}_{5}\right)^{\frac{1}{2}}}
$$

Pulse width for switches of DVR inverter is $\frac{T_{O}}{2}$. Pulse width for switches of AF inverter is $\frac{T_{5}}{2}$

Total Input current of ILBC is sum of the currents through $\mathrm{L}_{1}$ and $\mathrm{L}_{2}$.

$$
\mathrm{I}_{\mathrm{T}}=\mathrm{I}_{\mathrm{L} 1}+\mathrm{I}_{\mathrm{L} 2}
$$

The output of FOPID is as follows

$$
\mathrm{V}_{\mathrm{O}}(\mathrm{S})=\mathrm{E}(\mathrm{S})\left[\mathrm{K}_{1}+\frac{\mathrm{K}_{2}}{\mathrm{~S}^{\mathrm{m}}}+\mathrm{K}_{3} \mathrm{~S}^{\mathrm{n}}\right]
$$

Where $\mathrm{m}$ and $\mathrm{n}$ are fractions.

The output of PR based system is as follows.

$$
\mathrm{V}_{\mathrm{O}}(\mathrm{S})=\mathrm{E}(\mathrm{S})\left[\mathrm{K}_{4}+\mathrm{K}_{5} \frac{\omega}{\mathrm{s}^{2}+\omega^{2}}\right]
$$

$\mathrm{K}_{4} \& \mathrm{~K}_{5}$ are the constants of PR controller

\section{SIMULATION RESULTS}

Closed loop controlled UPQC Systems with PI, FOPID\& PR Controllers are modeled, simulated and their results are presented in this section. The simulation parameters are as follows.

Table-1: Parameters used for Simulation

\begin{tabular}{|c|c|}
\hline PARAMETER & VALUE \\
\hline Source Parameters $-\mathrm{R}_{1}, \mathrm{~L}_{1}$ & $0.1 \Omega, 3 \mathrm{mH}$ \\
\hline $\mathrm{R}_{2}, \mathrm{~L}_{2}$ & $0.5 \Omega, 30 \mathrm{mH}$ \\
\hline $\mathrm{R}_{3}, \mathrm{~L}_{3}$ & $0.8 \Omega, 40 \mathrm{mH}$ \\
\hline $\mathrm{C}_{\mathrm{in}}$ & $50 \mu \mathrm{F}$ \\
\hline $\mathrm{C}_{\mathrm{b}}$ & $9000 \mu \mathrm{F}$ \\
\hline $\mathrm{K}_{1}$ & 0.2 \\
\hline $\mathrm{K}_{2}$ & 0.5 \\
\hline $\mathrm{K}_{3}$ & 0.009 \\
\hline $\mathrm{K}_{4}$ & 0.9 \\
\hline $\mathrm{K}_{5}$ & 0.3 \\
\hline $\mathrm{Lt}_{1}, \mathrm{Lt}_{2}$ & $0.1 \mathrm{mH}, 0.1 \mathrm{mH}$ \\
\hline Load Parameters $-\mathrm{R}_{\mathrm{O}}, \mathrm{L}_{\mathrm{O}}$ & $200 \Omega, 100 \mathrm{mH}$ \\
\hline
\end{tabular}

\section{A. Closed Loop PI controlled ILBC based UPQC System}

Closed loop ILBC-UPQC system with PI controller is shown in Fig 3.1.Line impedance is split into two equal parts. Initial load and additional load are represented as series combination of $\mathrm{R} \& \mathrm{~L}$. Additional load is connected with the help of Breaker-1. Voltage of DVR is injected using Breaker -2. SAF part of UPQC is connected at the sending end of the system. The Output of DVR is injected into the line through a transformer. Load voltage is rectified to convert it to an analog signal. It is compared with the reference voltage. The error is applied to a PI controller. The output of PI controller is applied to pulse generator. The receiving end voltage 
is shown in Fig.3.2 and its peak value is $10^{4}$ Volts. The R.M.S receiving end voltage is shown in Fig.3.3 and its value is 6900 Volts. The Real power is shown in Fig 3.4 and its value is $4 * 10^{5}$ Watts. The Reactive power is shown in Figure 3.5 and its value is $6 * 10^{4}$ VAR.

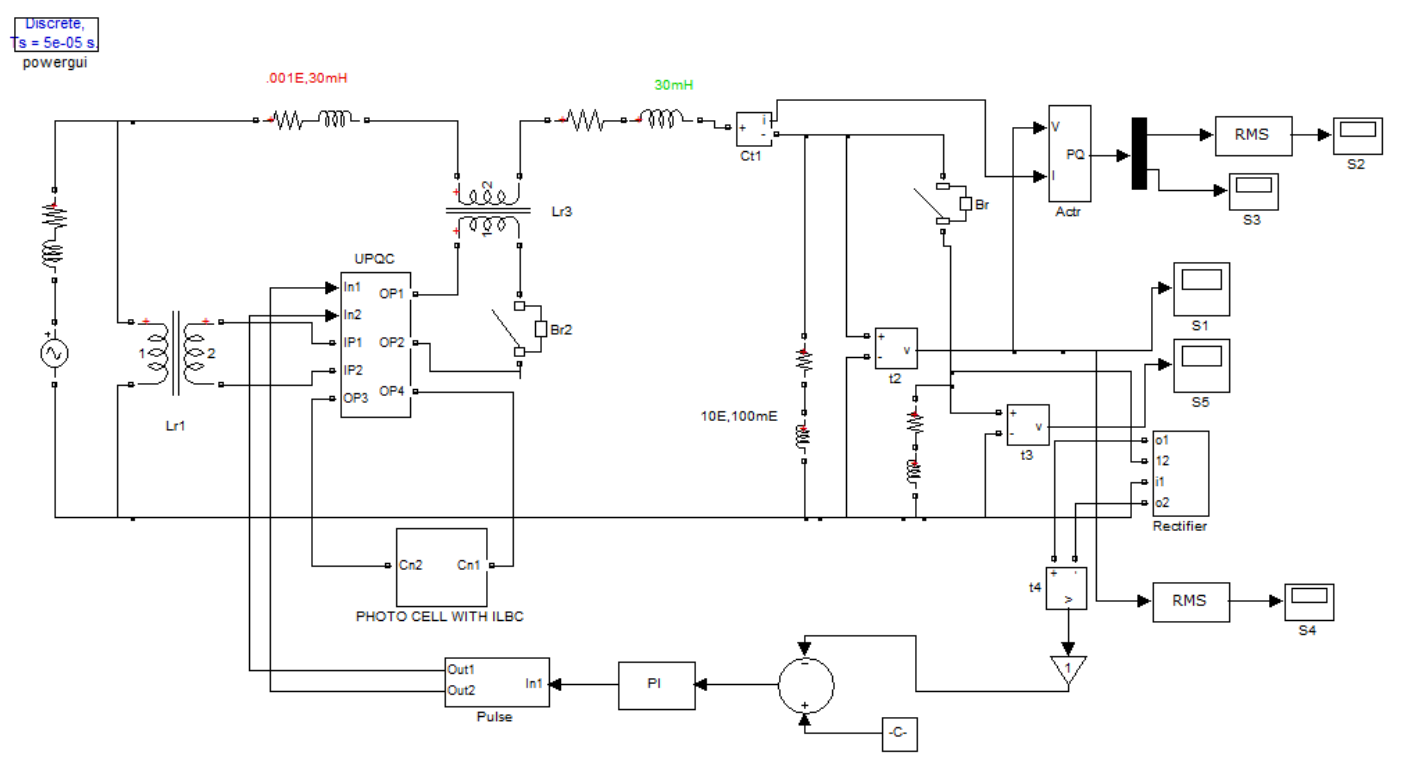

Fig.3.1: Closed loop ILBC-UPQC with PI Controller

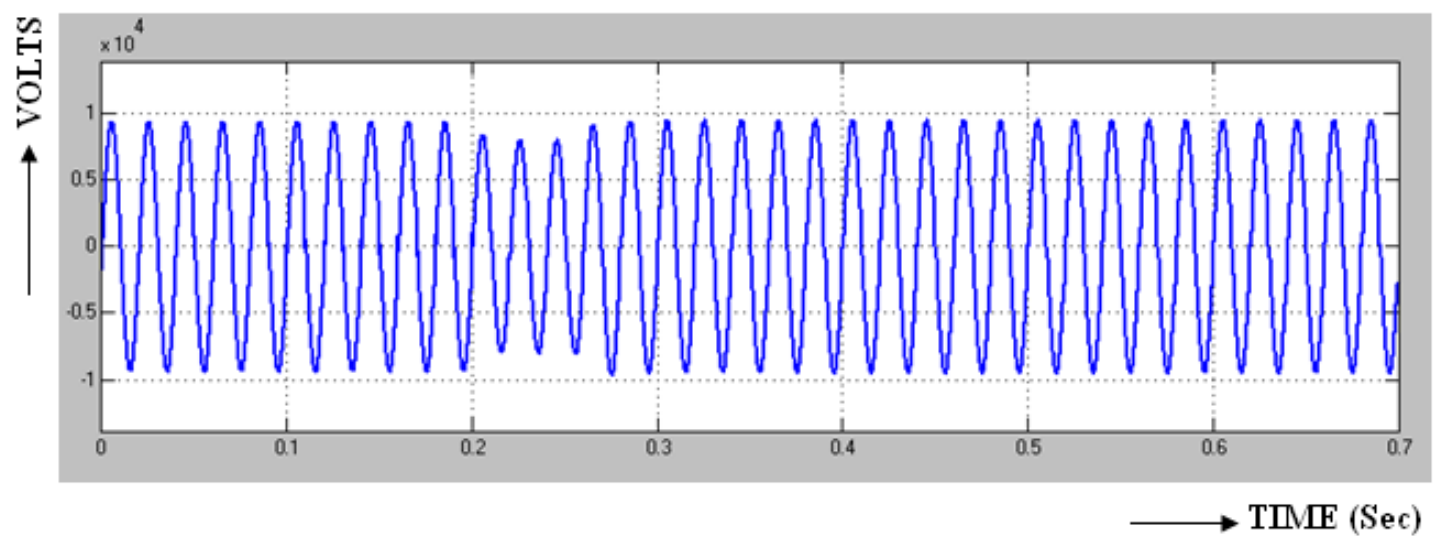

Fig.3.2: Receiving End Voltage

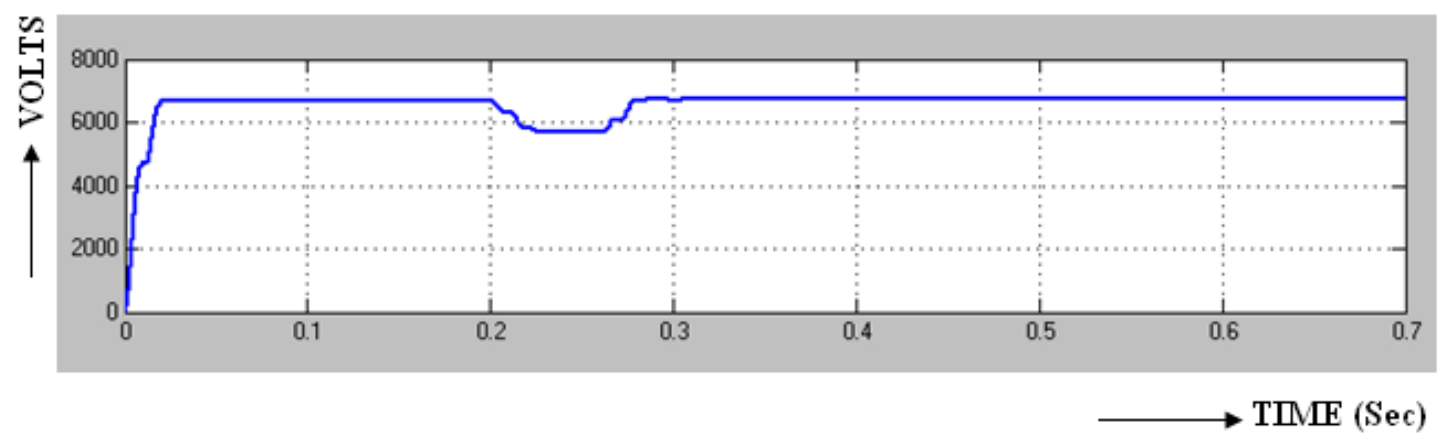

Fig.3.3: R.M.S Receiving End voltage 


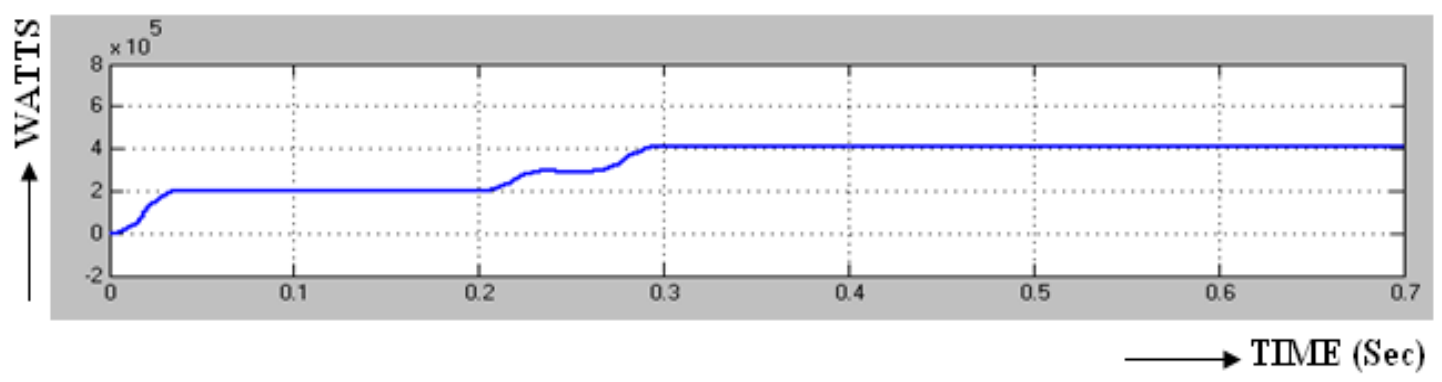

Fig.3.4: Real Power

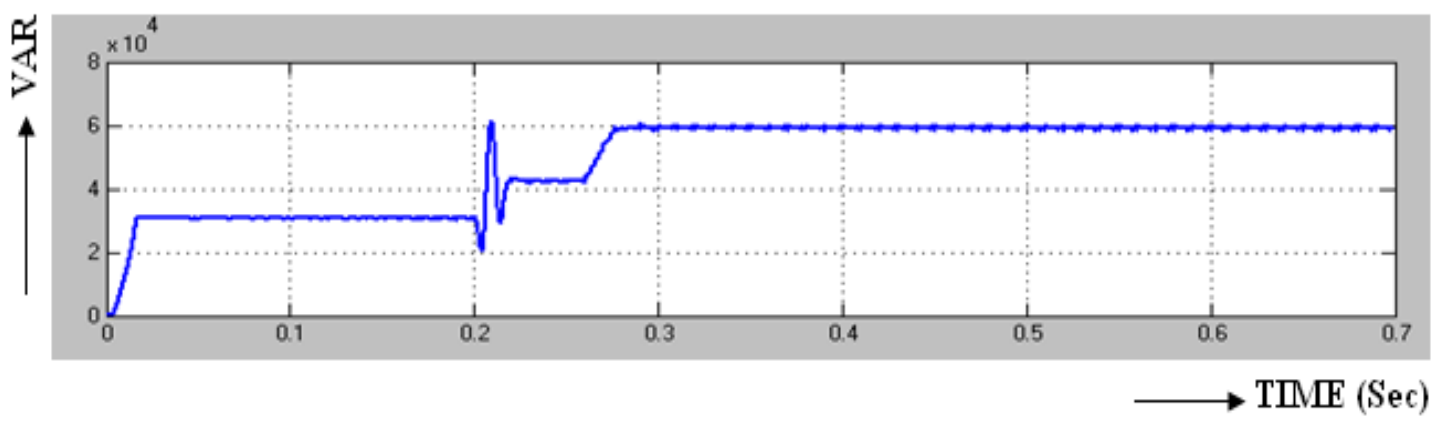

Fig.3.5: Reactive Power

\section{B. Closed Loop ILBC-UPQC System with FOPID Controller}

Closed Loop ILBC-UPQC system with FOPID controller is shown in Fig.4.1.The PI controller in Fig.3.1 is replaced by FOPID controller. The receiving end voltage is shown in Fig.4.2 and its peak value is $10^{4}$ V. The R.M.S receiving end voltage is shown in Fig.4.3. and its value is 6100 Volts. The receiving end voltage resumes normal value due to the injection of voltage by UPQC. The Real power is shown in Fig.4.4 and its value is $2.4 * 10^{5}$ Watts. The reactive power is shown in Fig 4.5 and its value is $4.4 * 10^{4}$ VAR.

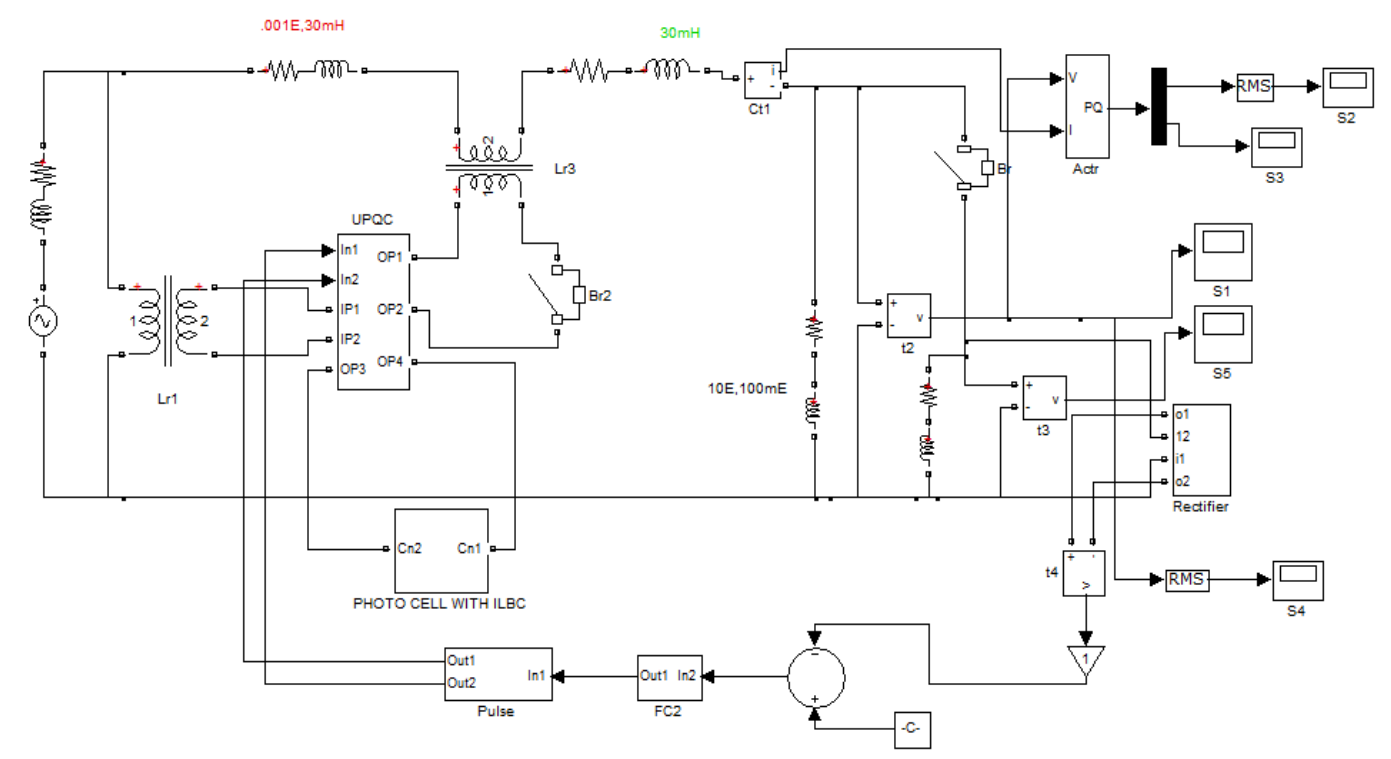

Fig. 4.1: Closed Loop ILBC-UPQC system with FOPID Controller 


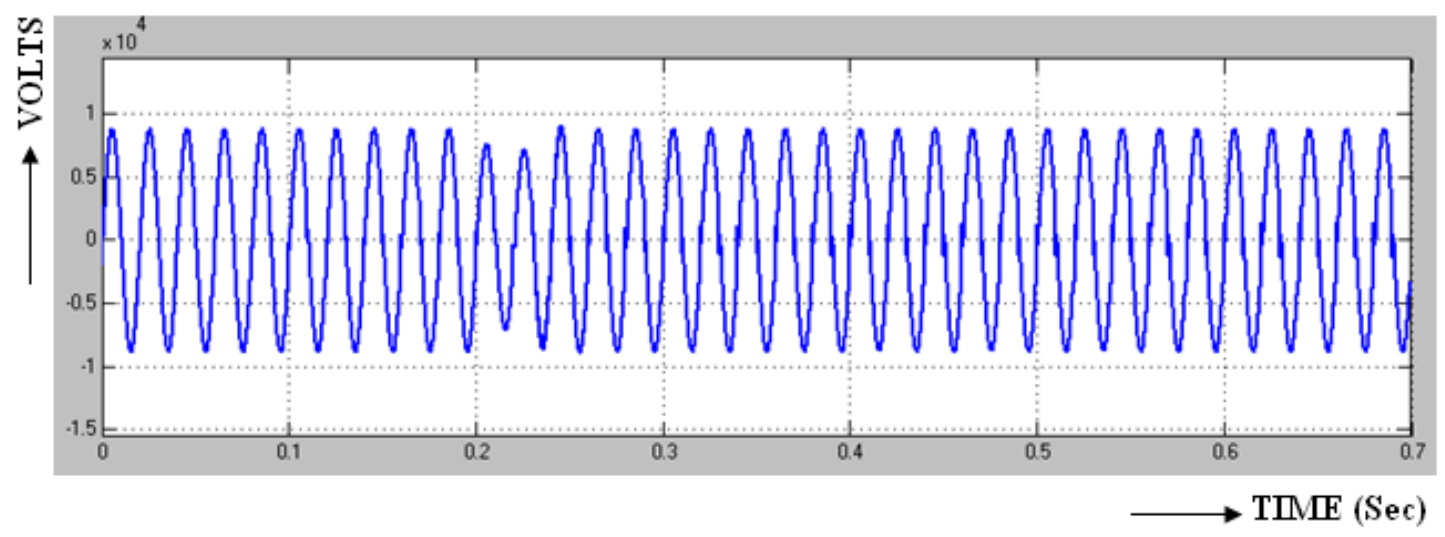

Fig.4.2: Receiving End voltage

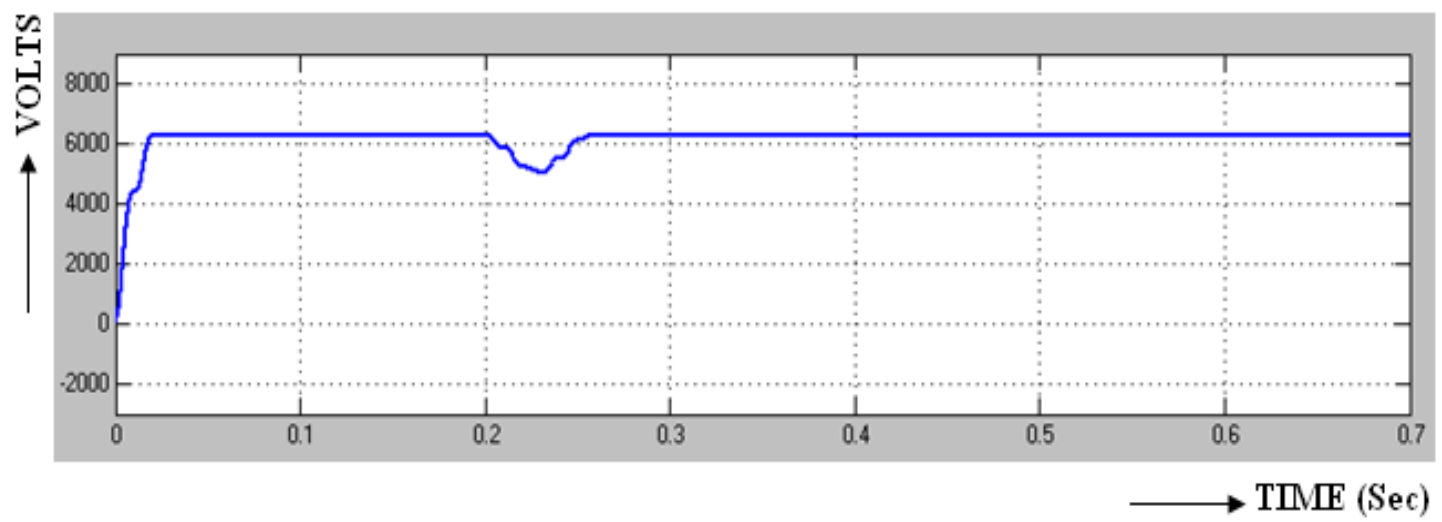

Fig.4.3: R.M.S. Receiving End Voltage

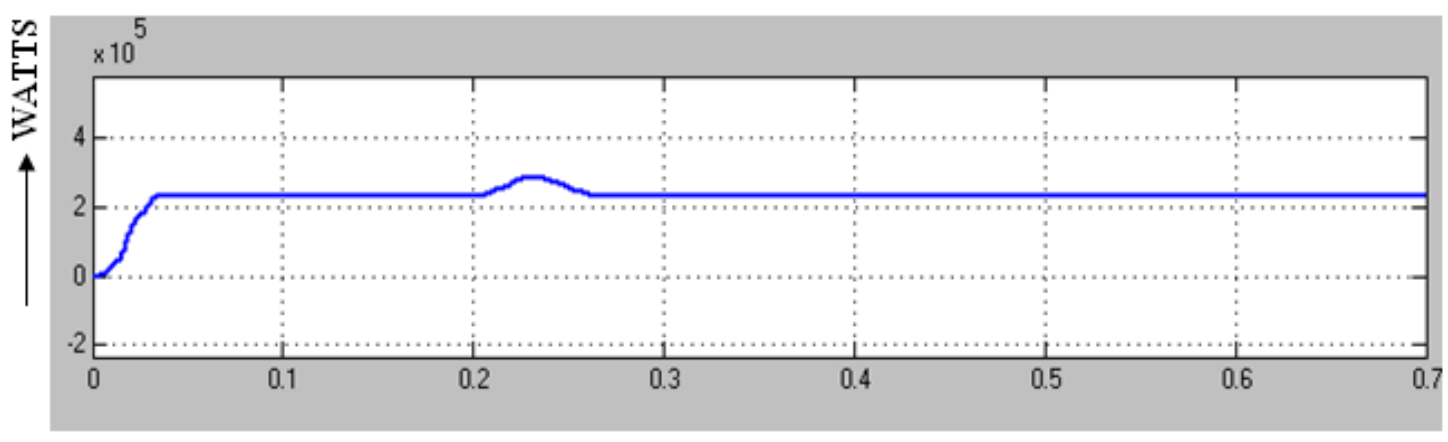

Fig.4.4: Real Power

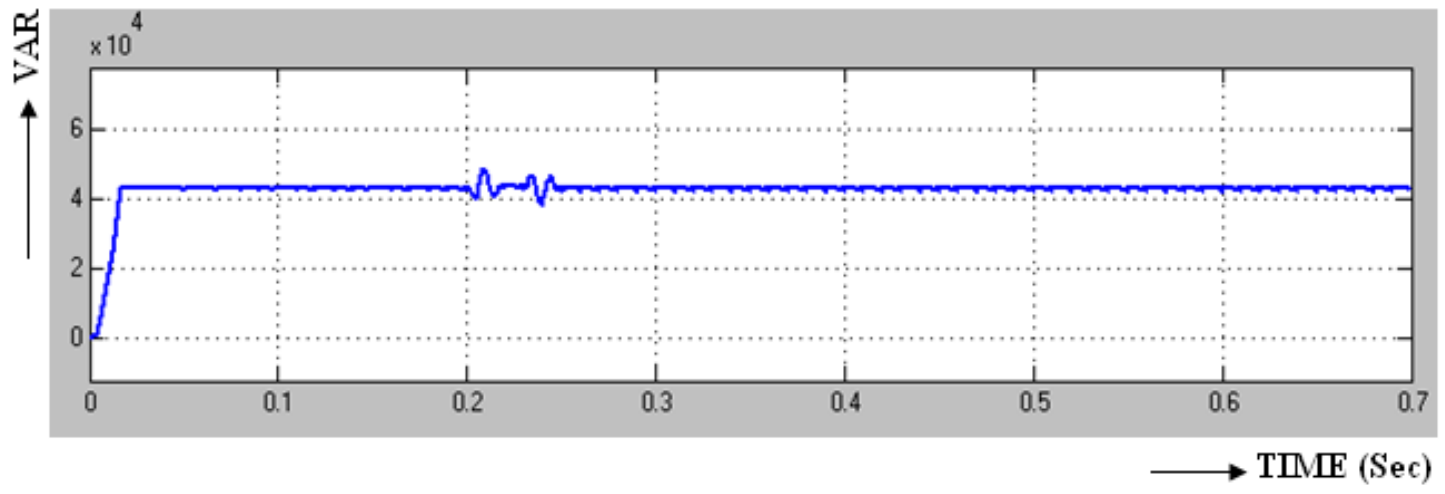

Fig.4.5: Reactive Power 


\section{Proposed Closed Loop ILBC-UPQC System with PR Controller}

Closed Loop ILBC-UPQC system with PR controller is shown in Fig.5.1. The FOPID is now replaced by PR controller. The receiving end voltage is shown in Fig.5.2 and its peak value is $10^{4} \mathrm{~V}$. The R.M.S receiving end voltage is shown in Fig.5.3. and its value is 6100 Volts. The Real power is shown in Fig.5.4 and its value is 2.4 $* 10^{5}$ Watts. The reactive power is shown in Fig 5.5 and its value is $4.4 * 10^{4}$ VAR.

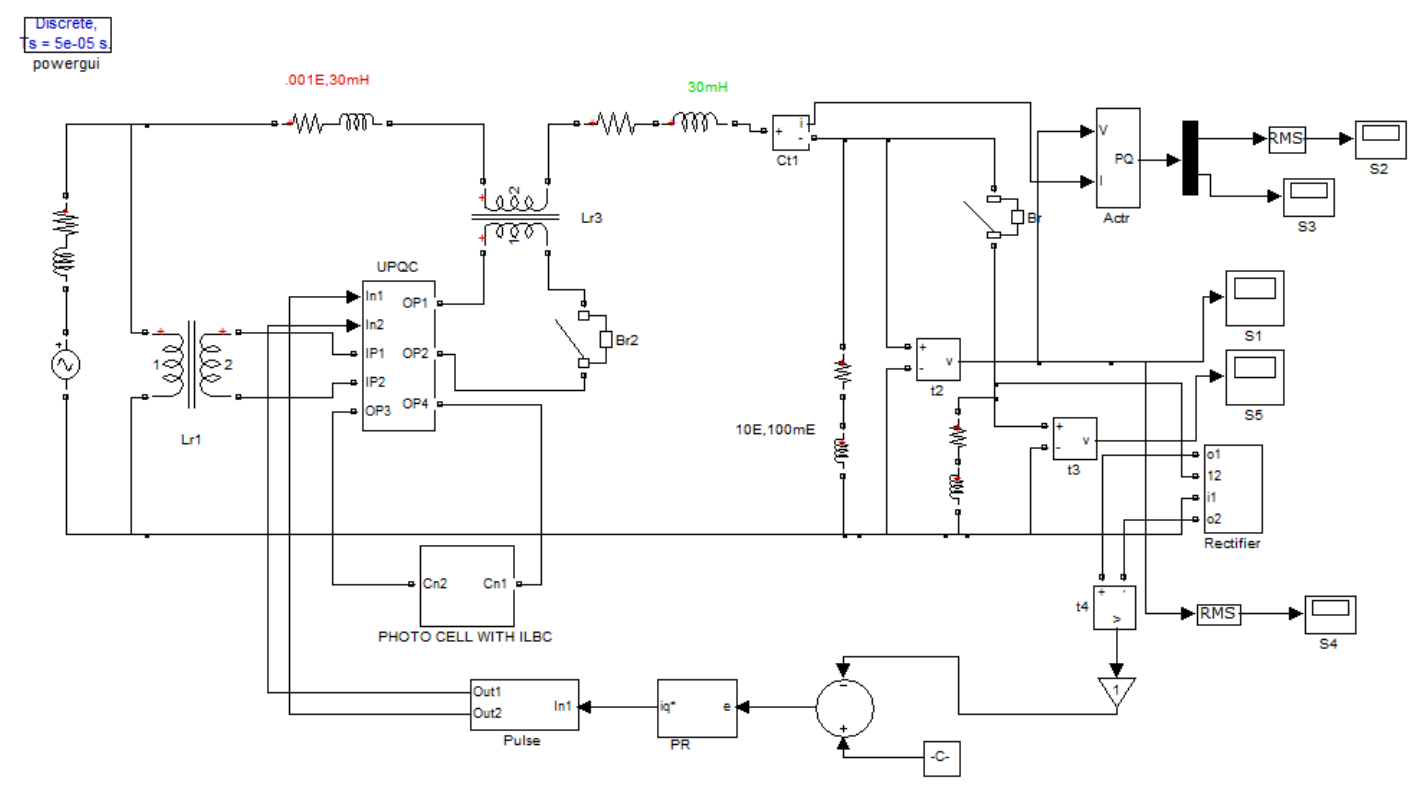

Fig. 5.1: Closed Loop ILBC-UPQC system with PR Controller

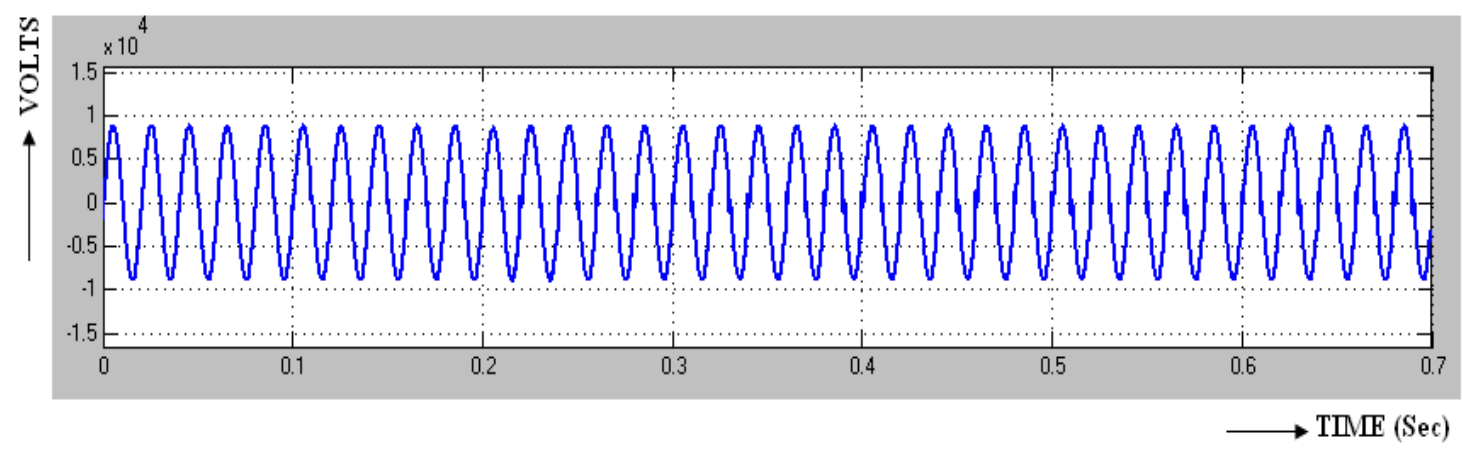

Fig.5.2: Receiving End voltage

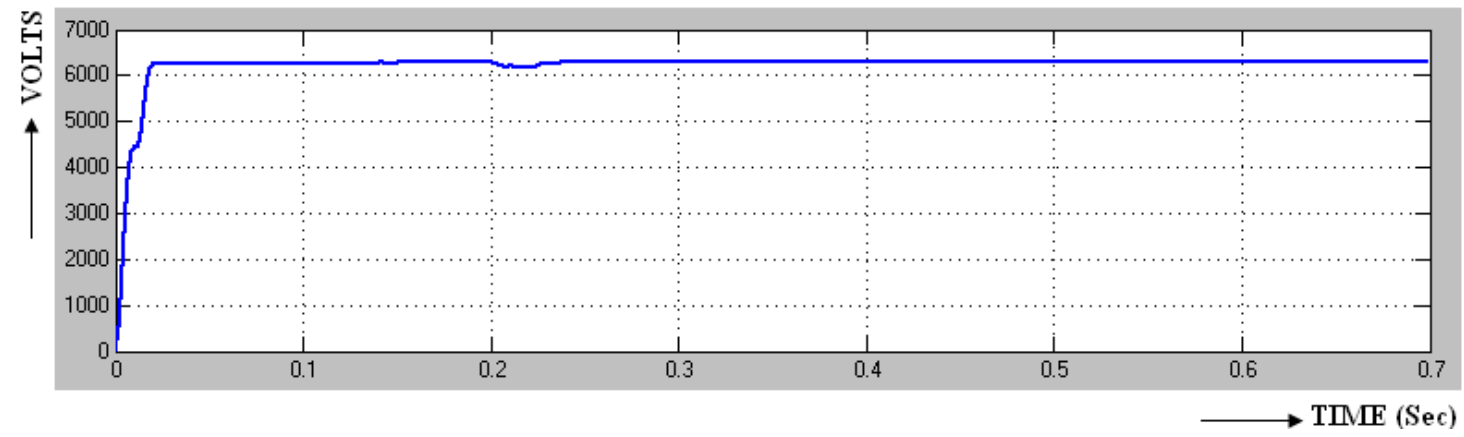

Fig.5.3: R.M.S. Output Voltage 


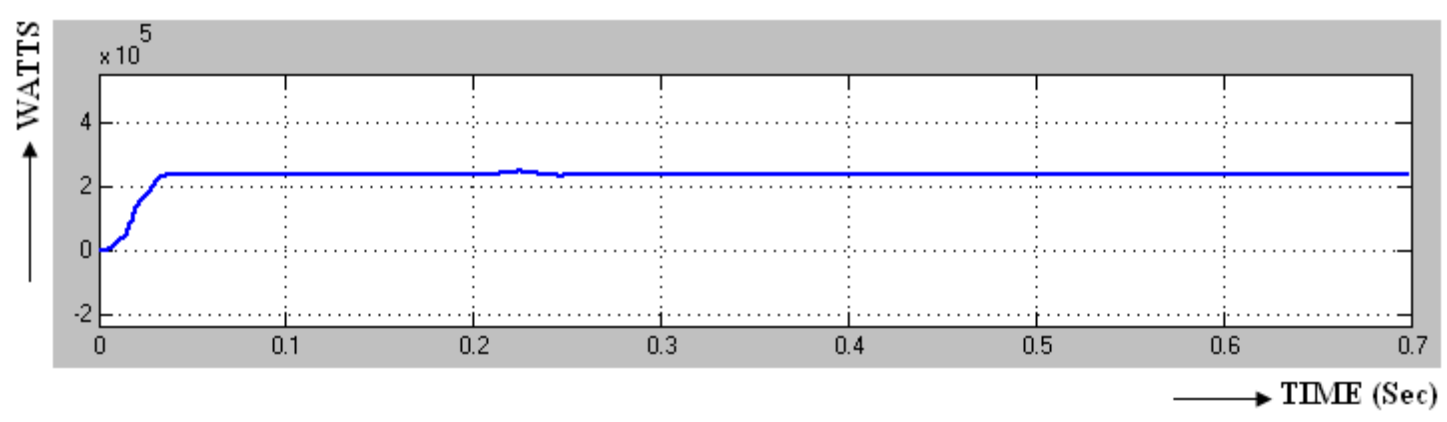

Fig.5.4: Real Power

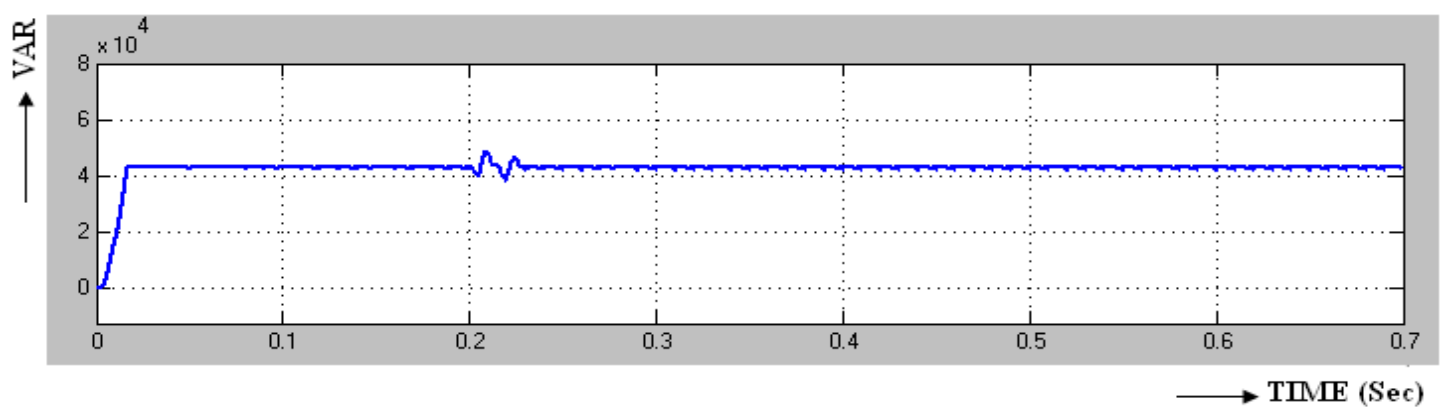

Fig.5.5: Reactive Power

From simulation results the observations of time domain parameters are as follows. The Rise time is $0.23 \mathrm{sec}$ in PI controller, it is reducesto $0.21 \mathrm{sec}$ with FOPID controller it turns to $0.207 \mathrm{sec}$ with PR controller. The Peak time is $0.26 \mathrm{sec}$ in PI controller, is reduced to $0.22 \mathrm{sec}$ with FOPID controller and it turns to $0.21 \mathrm{sec}$ with PR controller. The Settling time is $0.31 \mathrm{sec}$ in PI controller, is reduces to $0.25 \mathrm{sec}$ with FOPID controller and it turns to $0.23 \mathrm{sec}$ in PR controller. The steady state error is reduced from $5.3 \mathrm{~V}$ in PI controller, reduces to $2.7 \mathrm{~V}$ with FOPID controller and it turns to $1.8 \mathrm{~V}$ with PR controller. The comparison of time domain parameters is shown in Table -2 .

Table-2:Comparison of Time domain parameters with PI,FOPID \& PR Controllers

\begin{tabular}{|c|c|c|c|c|}
\hline Controllers & Rise time (s) & Peak time (s) & Settling time (s) & Steady state Error (V) \\
\hline PI & 0.23 & 0.26 & 0.31 & 5.3 \\
\hline FOPID & 0.21 & 0.22 & 0.25 & 2.7 \\
\hline PR & 0.207 & 0.21 & 0.23 & 1.8 \\
\hline
\end{tabular}

\section{CONCLUSIONS}

PI, FOPID \& PR based ILBC-UPQC systems are modeled and simulated using MATLAB and the results are analyzed. The results indicated that the response with PR is faster than that of PI\& FOPID Controlled ILBCUPQC systems. The settling time is reduced by $0.06 \mathrm{sec}$ when compared with PI and reduced by $0.02 \mathrm{sec}$ when compared with FOPID. The steady state error is reduced by 2.6 Volts by replacing PI with FOPID Controller and also reduced by $0.9 \mathrm{~V}$ by replacing FOPID with PR controller. The contributions of the present work are as follows: ILBC based UPQC is proposed for power quality improvement. The PR is proposed to enhance time domain response characteristics of ILBC based UPQC system. The advantages of proposed ILBC-UPQC system are reduced ripple and improved time domain response characteristics. The disadvantage is that the hardware of ILBC becomes twice that of HSUC.

The present work deals with comparison of PI, FOPID controlled ILBC-UPQC systems with PR based ILBC-UPQC system. The comparison between PR \& FUZZY controlled systems will be done at a later date.

\section{ACKNOWLEDGEMENTS}

The authors would like to thankProf. A. Lakshimi Devi, HOD - EEE, Prof. Dr. J. Karthikeyan Principal, M. Devarajulu,Registrar, Prof. Avula Damodaram, Vice - Chancellor, S.V. University, Tirupathi, A.P., India for providing the facilities to conduct Simulation studies in the Power Electronics Lab. 


\section{REFERENCES}

[1] B. Singh, K. Al-Haddad, and A. Chandra, "A review of active power filters for power quality improvement," IEEE Trans. Ind. Electron., vol. 45, no. 5, pp. 960-971, Oct. 1999.

[2] V. Khadkikar, "Enhancing electrical power quality using UPQC: A comprehensive overview," IEEE Trans. Power Electron., vol. 27, no. 5, pp. 2284-2297, May 2012.

[3] W. C. Lee, D.M. Lee, and T. K. Lee, "New control scheme for a unified power-quality compensator-Q with minimum active power injection," IEEE Trans. Power Del., vol. 25, no. 2, pp. 1068-1076, Apr. 2010.

[4] M. Yun, W. Lee, I. Suh, and D. Hyun, "A new control scheme of unified power quality compensator-Q with minimum power injection," in Proc. IEEE 30th Annu. Ind. Electron. Soc. Conf., Nov. 2-6, 2004, pp. 51-56.

[5] V. Khadkikar and A. Chandra, "UPQC-S: a novel concept of simultaneous voltage sag/swell and load reactive power compensations utilizing series inverter of UPQC," IEEE Trans. Power Electron., vol. 26, no. 9, pp. 2414-2425, Sep. 2011.

[6] V. Khadkikar and A. Chandra, "A new control philosophy for a unified power quality conditioner (UPQC) to coordinate load-reactive power demand between shunt and series inverters," IEEE Trans. Power Del., vol. 23, no. 4, pp. 2522-2534, Oct. 2008.

[7] D. Kisck, V. Navrapescu, and M. Kisck, "Single-phase unified power quality conditioner with optimum voltage angle injection for minimum VA requirement," in Proc. IEEE Int. Symp. Ind. Electron., Jun. 17-21, 2007, pp. 2443-2448.

[8] H. Ryoo, G. Rim, T. Kim, and D. Kisck, "Digital-controlled singlephaseunified power quality conditioner for non-linear and voltage sensitive load," in Proc. IEEE 30th Annu.Ind. Electron. Soc. Conf., Nov. 2-6, 2004, pp. 24-29.

[9] Y. Y. Kolhatkar, R. R. Errabelli, and S. Das, "A sliding mode controller based optimum UPQC with minimum VA loading," in Proc. PowerEng. Soc. Gen. Meeting, Jun. 12-16, 2005, pp. 871-875.

[10] Y. Y. Kolhatkar and S. Das, "Experimental investigation of a singlephaseUPQC with minimum VA loading," IEEE Trans. Power Del., vol. 22, no. 1, pp. 371-380, Jan. 2007.

[11] G. S. Kumar, P. H. Vardhana, B. K. Kumar, and M. K. Mishra, "Minimization of VA loading of unified power quality conditioner (UPQC)," in Proc. Power Eng., Energy Elect..Drives, Mar. 18-20, 2009, pp. 552-557.

[12] G. S. Kumar, B. K. Kumar, andM.M. Kumar, "Optimal VA loading of UPQC during mitigation of unbalanced voltage sags with phase jumps in three-phase four-wire distribution system," in Proc. Int. Conf. PowerSyst. Technol., Oct. 24-28, 2010, pp. 1-8.

[13] Podlubny, I.: Fractional - order systems and PI D controllers, IEEE Trans. On Automatic Control, vol.44, no.1, pp. $208213,1999$.

[14] Padula, F., Visioli, A., (2010a). Tuning rules for optimal PID and fractional -order PID controllers, Journal of Process Control ,doi:10.1016/j.jprocont.2010.10.006

[15] F. Merrikh - Bayat, M. Karimi - Ghartemani, "Method for designing FOPID stabilisers for minimum - phase fractional - order systems", IET Control Theory Appl., vol. 4, Issue 1, (2010), pp. 61 - 70.

[16] D. Zammit, C. SpiteriStaines, M. Apap, "Comparison between PI and PR Current Controllers in Grid Connected PV Inverters" International Journal of Electrical, Computer, Energetic, Electronic and Communication Engineering Vol:8, No:2, 2014, pp: 221-226.

\section{BIBLIOGRAPHY OF AUTHORS}

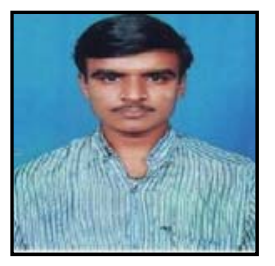

G.V. Prasanna Anjaneyulu has completed his B.E in 2005 from Andhra University and M.Tech in 2009 from NIT, Calicut. He has a teaching experience of ten years. Presently, he is a Research Scholar at S.V. University college of Engineering, Tirupathi, India. His research area is on Power Quality improvement in multibus systems. Mail-Id: gvp.anjaneyulu@gmail.com.

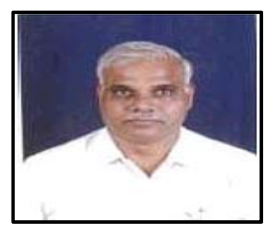

Dr. P. SangameswaraRaju has completed his B.E, M.Tech\&Ph.D from S.V.University college of Engineering. He has 30 years teaching experience. Currently he is working as a Professor in EEE Department, S.V. University college of Engineering, Tirupathi, India. His areas of interest are Power System Control and Renewable Sources of Energy. Mail-Id: raju_ps_2000@yahoo.com. 